7. Arai, M. Arquivos do Museu Nacional, Rio de Janeiro, 63(3). 2005

8. Zerfass, G.; Andrade, E. Terrae Didatica 3(1). 2008.

9. Guerra, R. M.; Tokutake, L. R.. Terrae Didatica 7(1). 2011.

10. Horne, D.; Holmes, J.; Rodriguez-Lazaro, J.; Viehberg, F.Developments in Quaternary Sciences, 17, 2-323. 2012.

11. Almeida, C.M. "Taxonomia, distribuição estratigráfica e paleocologia de ostracodes do Cretáceo superior, Coniaciano, ao Mioceno da bacia de Santos, margem continental sul do Brasil". Tese doutoramento, UnB. 2009

12. Horne, D.; Holmes, J.; Rodriguez-Lazaro, J.; Viehberg, F.Developments in Quaternary Sciences, 17. 2012

13. Riccomini, C.; Santa'Anna, L. G.; Tassinari, C.C.. Revista USP, 95. 2012.

14. Rodrigues, G. B. e Fauth, G. Terrae Didatica, 9, 34-49. 2013

15. Jaramillo, C. et al. "The origin of the modern Amazon rainforest: implications of the palynological and paleobotanical record". In: Amazonia: landscape and species evolution. Wiley-Blackwell. 2011.

16. Linhares, A. P. et al. Geología Colombiana. 36 (1) - Edición Especial. 2011

17. The Archean World, Peter Sawyer, Smithsonian Institute: http://ocean.si.edu/slideshow/ocean-throughout-geologic-time-image-gallery

18. Os autores agradecem ao Programa de Pós Graduação em Geociências, Instituto de Ciências Exatas e da Terra, Universidade Federal de Mato Grosso, campus Cuiabá. Ao CNPq pelo apoio à pesquisa (processo no. 476020/2013-1). Ao dr. Cláudio Magalhães, especialista em ostracodes, pela ajuda com a descrição dos pequenos crustáceos.

\section{PALEOBOTÂNICA: O QUE OS fÓSSEIS VEGETAIS REVELAM?}

\author{
Juliane Marques-de-Souza
}

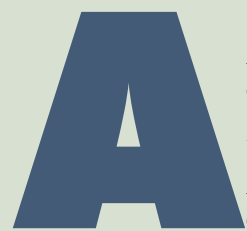

paleobotânica é uma área da paleontologia que, como tal, articula saberes de outras áreas do conhecimento, tais como a biologia e a geologia, para localizar, analisar e interpretar registros de organismos vegetais em rochas sedimentares formadas há milhares ou milhões de anos atrás. Para compreender, por exemplo, as dinâmicas ambientais que contribuíram para tamanha diversidade da flora atual, ou mesmo as novidades evolutivas associadas à saída do ambiente marinho e à conquista do ambiente terrestre, é preciso olhar para o passado. As rochas sedimentares são como fotografias desse passado e guardam com elas as memórias daquele tempo. Os paleontólogos e aqui, especificamente, os paleobotânicos são os profissionais treinados para olhar para essas rochas e decifrar seus registros, quando esses se referem a organismos do reino vegetal. De maneira geral, pode-se dizer que os paleobotânicos são como historiadores das plantas que buscam organizar a complexa pintura da história do reino vegetal (1).

Os restos vegetais fossilizados, objetos de estudo da paleobotânica, podem ser categorizados em macrofósseis e microfósseis vegetais (2). De maneira geral, pode-se dizer que o primeiro é representado por restos ou vestígios de estruturas vegetais macroscópicas, ou seja, visíveis a olho nu, tais como as folhas, os ramos, os lenhos, as sementes, as flores, os frutos, entre outras. O último é representado por estruturas microscópicas como grãos-de-pólen, esporos, cutículas etc, cuja visualização depende de aparelhos de magnificação como os microscópios e as lupas.

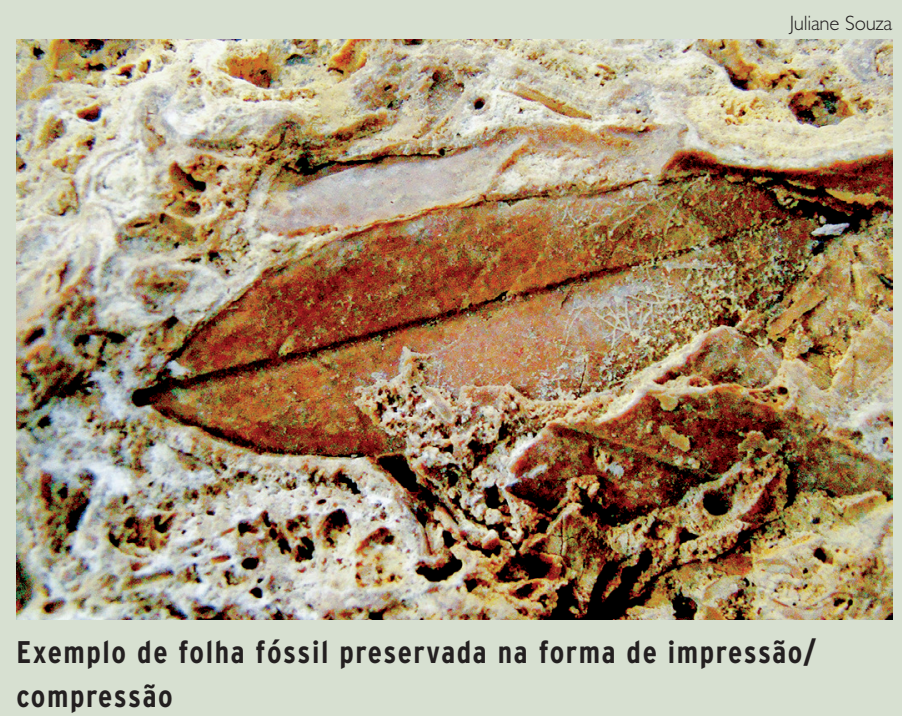


Nas últimas décadas, o estudo do registro fóssil associado aos estudos morfológicos e moleculares realizados em plantas atuais tem contribuído sobremaneira na compreensão da evolução da vida desde a proposição da teoria da seleção natural por Darwin (3). Contudo, mesmo diante de muitas gerações de pesquisadores que se dedicaram e se dedicam ao estudo das plantas fósseis, estas, diferentemente dos vertebrados (principalmente dos dinossauros), não são amplamente conhecidas pela população.

Mesmo dentre os estudantes de biologia ou geologia, seu potencial científico é muitas vezes desconhecido. Nos currículos escolares, e até mesmo no ensino superior, esse conteúdo é frequentemente negligenciado, mesmo persistindo o estudo da disciplina de botânica. E, se conteúdos como anatomia e morfologia vegetal de plantas atuais são elementos contidos no currículo, então o conhecimento sobre a paleobotânica passa a ser também fundamental para a compreensão lógica desses conceitos (4), visto que a paleobotânica, em suas várias formas, permanece como o único método pelo qual a história dos grupos vegetais pode ser visualizada e documentada (5).

A PALEOBOTÂNICA NA PRÁTICA Sabe-se, hoje, que as plantas foram as responsáveis por "preparar" o ambiente terrestre para que a evolução da vida animal fosse possível, contribuindo, por exemplo, com a oxigenação da atmosfera primitiva (6;7). Já se conhece o momento na história da vida na Terra em que os grandes grupos vegetais se originaram, o momento da máxima diversificação desses grupos e, em alguns casos, quando eles foram extintos (8). No entanto, não somente aos estudos evolutivos serve a paleobotânica.

Uma das primeiras e mais difíceis tarefas dos paleobotânicos está no reconhecimento e na reconstrução dos próprios organismos vegetais. Isso porque a maior parte do registro fóssil de plantas contém restos desarticulados desses organismos, ou seja, folhas desconectadas de ramos, ramos desconectados de caules e estruturas reprodutivas dispersas (frutos, sementes, grãos de pólen e esporos). Diante desse cenário, muitos pesquisadores dedicam-se anos a recompor esses organismos. Para isso, buscam nos registros amostras que contenham partes conectadas e, como um grande quebra-cabeça, reconstroem a planta em sua totalidade.

Um exemplo bem sucedido de reconstrução vegetal é o da Glossopteris. A flora Glossopteris é indicadora global de um momento específico da história da Terra em que os continentes estiveram unidos em uma única massa continental chamada Pangea. Em depósitos formados no período Permiano, em países como Brasil, Índia, Austrália e África do Sul e na Antártica é possível encontrar abundantes registros de partes representantes dessa flora. E, em virtude da sua importância na compreensão da evolução do reino vegetal, muitos pesquisadores do mundo dedicam-se ao estudo desse material. Essa abundância de registro associada ao esforço coletivo no estudo dessa planta permitiu, já em 1977, a primeira proposição da organização estrutural da Glossopteris (9).

Outro aspecto a se destacar é que a preservação de restos vegetais, assim como de outros organismos, depende da sua resistência à de-

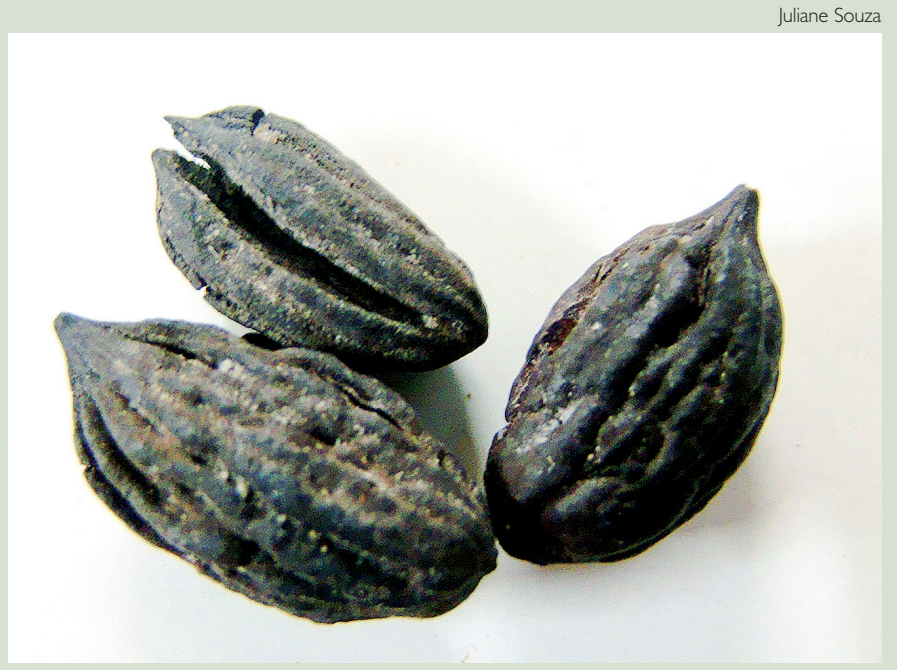

Diásporos/ sementes fósseis mineralizadas

composição, ao transporte e a fatores físicos e químicos associados à transformação desse organismo em um fóssil (fossildiagênese). Assim, ela varia enormemente dependendo da estrutura do órgão vegetal e do tipo de ambiente ao qual foi exposto (10). Comparativamente, lenhos lignificados e grãos de pólen, estes últimos em virtude da presença da esporopolenina, tendem a ser mais resistentes ao transporte e ao retrabalhamento do que folhas as quais, dependendo da espécie, podem ser mais delicadas, porém normalmente são produzidas em abundância pelas "plantas-mãe" (11). Um depósito fossilífero contendo registro dessas estruturas menos resistentes ou de plantas preservadas em posição de vida são excelentes indicativos do local em que esses organismos viviam.

Portanto, uma vez preparados para identificar e interpretar esses registros, os paleontólogos são capazes de, por vezes, sugerir reconstruções paleoambientais e compreender como as paisagens evoluíram ao longo dos milhões de anos de existência das plantas na Terra. Um caso interessante para exemplificar a aplicação da paleobotânica em reconstruções paleoambientais é o estudo desenvolvido por pesquisadores russos com o espécime de mamute pleistocênico (Mammuthus primigenius Blumenbach, 1799) apelidado de "Yuka", descoberto em 2010 na Sibéria. Por meio da análise de grãos de pólen e de macrofósseis vegetais, encontrados na mesma área de onde o espécime de mamute foi coletado, os pesquisadores reconstruíram a vegetação à época sugerindo tratar-se de um mosaico tundra-estepe combinado com prados enriquecidos por vegetação de estepe (12).

A biologia e a ecologia de muitos grupos vegetais do passado também podem ser conhecidas a partir das análises desses registros fósseis. Estruturas caulinares lignificadas, por exemplo, sugerem resistência e crescimento secundário (altura); o tamanho do limbo foliar pode sugerir, entre outras coisas, a posição no estrato florestal; a presença de estruturas reprodutivas aladas 
pode dar indícios da sua estratégia de dispersão. E, o conjunto dessas informações permite reconstruir os ambientes ou a biologia de grupos que há muito deixaram de existir. Vale ressaltar, por outro lado, que essa tarefa não é simples e acaba tornando-se mais difícil justamente quando se trata de grupos que não apresentam representantes vivos atuais (13).

A descoberta de uma floresta de esfenófitas do tipo Calamites Suckow, 1784, preservada em posição de vida, é um exemplo recente da aplicabilidade ecológica dos estudos paleobotânicos. Tendo sido encontrados em depósitos sedimentares do Carbonífero superior do Reino Unido, os quais foram interpretados como provenientes de ambientes de planície costeira com influência marinha, as mais de uma centena de espécimes sugerem certa tolerância desse grupo de plantas a ambientes salinos. Essa tolerância pode ser observada a partir de sucessivos registros de recolonização, por meio da produção de uma regeneração adventícia após uma série de episódios de incursões salobras no ambiente de vida desses organismos (14).

Por fim, um último exemplo da aplicação da paleobotânica, escolhido dentre tantos outros que não foram abordados neste artigo, é na paleoclimatologia. Da mesma maneira que a partir dos registros fósseis vegetais é possível reconstruir um ambiente, é também possível reconstruir o clima do planeta no passado, bem como reconhecer suas mudanças ao longo do tempo.

As plantas são excelentes indicadores das condições climáticas às quais foram submetidas em vida. Isso porque além de serem sensíveis às modificaçôes climáticas em escala continental (15), algumas estruturas morfo-anatômicas específicas evidenciam mecanismos de sobrevivência em diferentes condiçôes de umidade, incidência solar, temperatura, entre outros. A densidade de estômatos presentes na superfície foliar, por exemplo, é utilizada para inferir mudanças nas concentrações atmosféricas de $\mathrm{CO}_{2}$ em diferentes períodos geológicos (16). Ou, a ocorrência de paleoincêndios, que também fica marcada no registro fóssil vegetal, por ser importante indicadora das mudanças climáticas ocorridas no passado (17), tem sido ferramenta para proposiçôes relacionadas às alterações nos níveis de oxigênio atmosférico global (18) ao longo da história da Terra.

Assim, longe de tentar abordar neste artigo todas as aplicaçōes e interfaces da paleobotânica, o que se pretendeu foi dar ao leitor uma visão ampla da complexidade dessa disciplina e o quanto ela pode contribuir na compreensão da dinâmica ambiental terrestre. Diante do exposto, fica evidente que as mudanças no reino vegetal, ao longo da história da vida na Terra, guardam ainda muitas surpresas, as quais serão conhecidas pouco a pouco, à medida que os estudos avancem.

Juliane Marques de Souza é bióloga, doutora em geociências, na área de concentração da paleobotânica, pela Universidade Federal do Rio Grande do Sul (UFRGS). Professora da Universidade Estadual de Roraima (UERR), sendo professora permanente do Programa de Pós-Graduação em Ensino de Ciências no qual atua na linha de divulgação científica.

\section{REFERÊNCIAS}

1. Taylor, T.N.; Taylor, E.L. \& Krings, M. Paleobotany: the biology and evolution of fossil plants. 2 ed. Editora Elsevier. 2009.

2. Martin, R.E. Taphonomy:a process approach. Reino Unido: Cambridge. (Cambrige Paleobiology Serie; 4), 1999.

3. Willis, K. J. \& McElwain, J. C. The evolution of plants. New York: Oxford University Press. 2002

4. Giebel, K. P. "Plant fossils in the laboratory". Disponível em: http:// www.ableweb.org/volumes/vol-3/9-giebel.pdf

5. Taylor, T.N.; Taylor, E.L. \& Krings, M. Op.cit., p. 2.

6. Spicer, R. A. "Plant taphonomic process". In: Allison, P. A. \& Brigs, D. E. "Taphonomy: realeasing the data locked in the fossil record". Topics in Geobiology. New York: Plenum Press. 1999, p.71-95.

7. Gensel, P. "Introduction". In: Gensel, P. \& Edwards, D. Plants invade the land: evolutionary and environmental perspectives, 2001, p.1.

8. Taylor, T.N.; Taylor, E.L. \& Krings, M. O.cit.

9. Gould, R. E. \& Delevoryas, T. "The biology of Glossopteris: evidence form petrified seed-bearing and pollen-bearing organs". Alcheringa 1: 387 - 399, 1977

10. Spicer, R. A. Op. cit., p.76.

11. Martin, R. E. Op. cit., p.93.

12. Rudaya, N.; Protopopov, A.; Trofimova, S.; Plotinikov, V.; Snezhana, Z. 'Landscape of the 'Yuka' mammoth habitat: a palaeobotanical approach". Review of Palaeobotany and Palynology, 2015, 214, pp. 1-8.

13. Iannuzzi, R. \& Vieira, C. E. L. Paleobotânica. Editora da UFRGS, 2005

14. Falcon-Lang, H. J. "A calamitalean forest preserved in growth position in the Pennsylvanian coal measures of South Wales: implications for palaeoecology, ontogenyand taphonomy". Review of Palaeobotany and Palynology, 2015, 214: 51-67.

15. Guerra-Sommer, M. \& Pires, E. T. "Conceitos e perspectivas". In: Carvalho, I. S (org.) Paleontologia: paleovertebrados, paleobotânica. Volume 3. 3. ed. Rio de Janeiro: Interciência, 2011, pp. 217-218.

16. Schmidt, I. D.; Guerra-Sommer, M.; Bernardes-de-Oliveira, M. E. “Variation in stomatal numbers of Glossopteris leaves from the lower Permian of Paraná Basin, Brazil". Revista Brasileira de Paleontologia 14(2): 137-148, maio/agosto 2011.

17. Jasper, A.; Guerra-Sommer, M.; Uhl, D.; Bernardes-de-Oliveira, M.E.C.; Ghosh, A. K.; Tewari, R. \& Secchi, M. I. "Palaeobotanical evidence of wildfire in the upper Permian of India: macroscopic charcoal remains from the Raniganj formation, Damodar basin". The Palaeobotanist, 2012, 61: 75-82

18. Abu Hamad A. M. B.; Jasper, A.; Uhl, D. “The record of Triassic charcoal and other evidence for palaeo-wildfires: signal for atmospheric oxygen levels, taphonomic biases or lack of fuel?". International Journal of Coal Geology, 2012, (96-97):60-71 